\title{
Fine-scale oxygen variability in a stratified estuary: patchiness in aquatic environments
}

\author{
M. J. Atkinson ${ }^{1}$, T. Berman ${ }^{2}$, B. R. Allanson ${ }^{3} \&$ J. Imberger ${ }^{4}$ \\ ${ }^{1}$ Department of Zoology, University of Western Australia, 6009 Nedlands, Western Australia, Australia \\ ${ }^{2}$ Kinneret Limnological Laboratory, PO Box 345, 14102 Tiberias, Israel \\ ${ }^{3}$ Institute for Freshwater Studies, Rhodes University, 6140 Grahamstown, South Africa \\ ${ }^{4}$ Department of Civil Engineering, University of Western Australia, 6009 Nediands, Western Australia, Australia
}

\begin{abstract}
Vertical and horizontal scales of oxygen patches in a strongly stratified, productive estuary were determined using current drogues and a CTD profiler equipped with a rapid response oxygen sensor. For the deep water layer, vertical and horizontal dimensions of oxygen patches were 1 to $2 \mathrm{~m}$ and 100 to $200 \mathrm{~m}$ respectively. Vertical diffusivities were also mapped from fine-scale measurements of temperature and salinity using calculated quantities of buoyancy frequency and dissipation rate per unit mass. Oxygen patch size was consistent with a model relating the vertical length scale of oxygen variability with vertical diffusivity, and the ratio of oxygen concentration differences between patches with the rate of oxygen metabolism. The observed oxygen patch size was consistent with the hypothesis that local oxygen production was balanced by vertical mixing. Vertical and horizontal distributions of soluble reactive phosphate were also determined but with greatly reduced resolution. Phosphate showed vertical variability consistent with the idea that it was extremely patchy. Largescale horizontal distributions of mean oxygen and phosphate concentrations revealed a stoichiometery consistent with the remineralization of organic material in estuary bottom water.
\end{abstract}

\section{INTRODUCTION}

Aquatic organisms are unevenly distributed in nature (Steele 1978). Heterogeneous distributions of planktonic and benthic organisms can be caused by physical processes, for example Langmuir circulation, fronts, billowing, and in benthic systems, currents, wave stress, and changes in substratum. Uneven distributions can also be biologically mediated due to differential settlement and growth rates, animal migration, chemo- and photo-sensory responses of bacteria and phytoplankton etc. Thus, both physical and biological factors can contribute to the spatial variability of organisms and chemical parameters reflecting their presence. In this paper we consider the spatial variability of dissolved compounds determined by biological and physical processes.

Changes in the mean concentrations of biogeochemical compounds are a result of differing combinations of average physical and biogeochemical processes. Of necessity, most estimations of major oceanic chemical and biological processes have been based on mean values without much consideration for variability (Platt \& Harrison 1985). Recently, attention has focussed on the spatial and temporal variability of plankton (Steele 1978), and also how the variability of biogeochemical quantities might influence sampling (Imberger et al. 1983) or the determinations of average rates (Platt \& Harrison 1985). In regions of a water body where physical mixing processes are relatively fast compared to biological processes, the spatial and temporal distribution and variability of a biologically generated parameter will be determined by mixing. In contrast, where mixing is relatively slow, biological rates will also affect parameter distribution and variability. In the ocean and other stratified water bodies, vertical mixing rates fluctuate 4 to 5 orders of magnitude and biomass specific biological rate processes vary over at least 3 orders of magnitude (Steele 1978). Thus, assigning the relative influence of physical or biological forcing on the measured variability of important ecosystem parameters can be extremely difficult.

In the present study we have been able to map finescale variability of vertical diffusivities and oxygen $\left(\mathrm{O}_{2}\right)$ concentrations in a stratified, biologically productive estuary. Oxygen was chosen for this study because we have developed a CTD- $\mathrm{O}_{2}$ probe with a very fast response oxygen sensor. This probe enabled us to 
sample oxygen at vertical scales of 2 to $5 \mathrm{~cm}$, giving a very high resolution of the vertical distribution of a 'non-conservative' parameter in the water column. We consider the dynamic evolution of ephemeral patches of biochemical substances which give rise to the mean changes of these quantities.

\section{Theory}

Distinct volumes of water containing a biogeochemical substance, here called patches, are discerned as measurable changes in the concentration of that quantity. Thus to delineate a patch of a substance we must be able to measure its variability. Every material will have its own characteristic patch size, depending on vertical and horizontal physical mixing rates and the rate at which the substance is consumed or produced within the water column or at the boundary of the water (Fischer et al. 1979; they use the term 'cloud' instead of patch). The size of a patch can be estimated by comparing the time scale of the physical mixing process with that of the 'non-conservative' processes.

The time scale to mix water a given vertical distance $\left(\mathrm{T}_{z}\right)$ can be estimated by dividing the square of the vertical length over which the water is mixed $\left(\mathrm{L}^{2}\right)$ by the vertical mixing rate $\left(K_{z}\right)$ (Fischer et al. 1979):

$$
\mathrm{T}_{2}=\mathrm{L}^{2} / \mathrm{K}_{2}
$$

Likewise the time scale for a biological reaction, $T_{m}$, (in our case, the production or consumption of oxygen or phosphate) can be stated as the concentration of the metabolite $\left(\mathrm{C}_{0}\right)$ divided by the metabolic rate $(\mathrm{a})$, or:

$$
\mathrm{T}_{\mathrm{m}}=\mathrm{C}_{\mathrm{o}} / \mathrm{a}
$$

As has been stated, in order to discern the patches of oxygen, we must be able to measure variability of oxygen concentrations. Therefore, to determine the time scale of the biological reaction, rather than using the absolute value of the oxygen concentration in the numerator of Eqn (2) we used the observed differences in oxygen concentration between patches. Thus $T_{m}$ is the time period it takes to create a minimum measurable oxygen concentration difference between patches. Using these time scales, 2 independent processes which both act to affect variability in the same parameter can be compared (Imberger 1977, Platt et al. 1981, Pomeroy \& Imberger 1981).

Mixing processes tend to smear patches while metabolic processes tend to create them. Distinct patches develop when the average mixing rate is approximately equal to the metabolic rate. When vertical mixing processes are much faster than metabolically induced changes in oxygen, then $\mathrm{T}_{z}$ will be much less than $T_{m}$ i conversely when oxygen metabolism is much more rapid than mixing, then $T_{z}$ is much larger than $T_{m}$. When the time scales of the biological and physical processes become similar a characteristic critical patch size, $L$, can be observed (for steady plankton patches see Skellam 1951, Kierstead \& Slobodkin 1953, Denman \& Platt 1976, Okubo 1977, Platt et al. 1981, Lewis \& Platt 1982). By setting $T_{z}$ equal to $T_{m}$, $L$ can be estimated:

$$
\mathrm{L}=\left(\mathrm{C}_{0} \mathrm{~K}_{\mathrm{z}} / \mathrm{a}\right)^{1 / 2}
$$

Thus the length to maintain a patch is determined by the relative importance of the time scales for mixing and the biological reaction. (Note that in the above, we estimate only a length scale between patches or layers.)

In a strongly stratified estuary that is also highly productive we can estimate the height (vertical thickness) of a patch of oxygen using Eqn (3). As a sample calculation, if respiration balances oxygen production for the entire water column and proceeds at a rate of approximately 20 mmoles $\mathrm{O}_{2} \mathrm{~m}^{-2} \mathrm{~h}^{-1}$ (light saturated productivity with an efficiency of $2 \%$ of incident solar radiation) then over a $10 \mathrm{~m}$ water column the approximate volume for in situ oxygen consumption is 2 mmoles $\mathrm{O}_{2} \mathrm{~m}^{-3} \mathrm{~h}^{-1}$. For a change in oxygen concentration of 50 mmoles $\mathrm{O}_{2} \mathrm{~m}^{-3}$, the biological reaction time scale $\left(\mathrm{C}_{\mathrm{o}} / \mathrm{a}\right)$ approximates $25 \mathrm{~h}$. Assuming a vertical diffusivity in the deep water of $10^{-5} \mathrm{~m}^{2} \mathrm{~s}^{-1}$ (or 0.86 $\mathrm{m}^{2} \mathrm{~d}^{-1}$ ), then $\mathrm{L}$ is about $0.90 \mathrm{~m}$. Given that Eqn (3) is a result of dimensional analysis of a differential equation in which the physical mixing term is of equal magnitude to the metabolic term, we might expect to measure about 50 mmole $\mathrm{O}_{2} \mathrm{~m}^{-3}$ variability in the vertical on scales of $10^{\prime} \mathrm{s}$ of cms to several meters.

In this study we measured vertical profiles of oxygen concentrations on a scale of $2 \mathrm{cms}$. The vertical variability of oxygen was used to measure $L$ and the difference in oxygen concentration between the patches. Concomitantly we estimated vertical diffusivities $\left(K_{z}\right.$ as described below) by measuring the fine-scale (cms) vertical distribution of conductivity (salinity) and temperature. Knowing $L, K_{z}$, and the difference of oxygen between the patches, we estimate the oxygen metabolic rate to show that this analysis gives reasonable values for both respiratory uptake and photosynthetic evolution of oxygen. We also show that the size of the oxygen patches is consistent with shearinduced mixing.

\section{EXPERIMENTAL SITE AND METHODS}

The experiment was conducted in a relatively deep (10 to $16 \mathrm{~m}$ ) straight section of the Swan River Estuary, Western Australia, named Blackwall Reach (Fig. 1). 


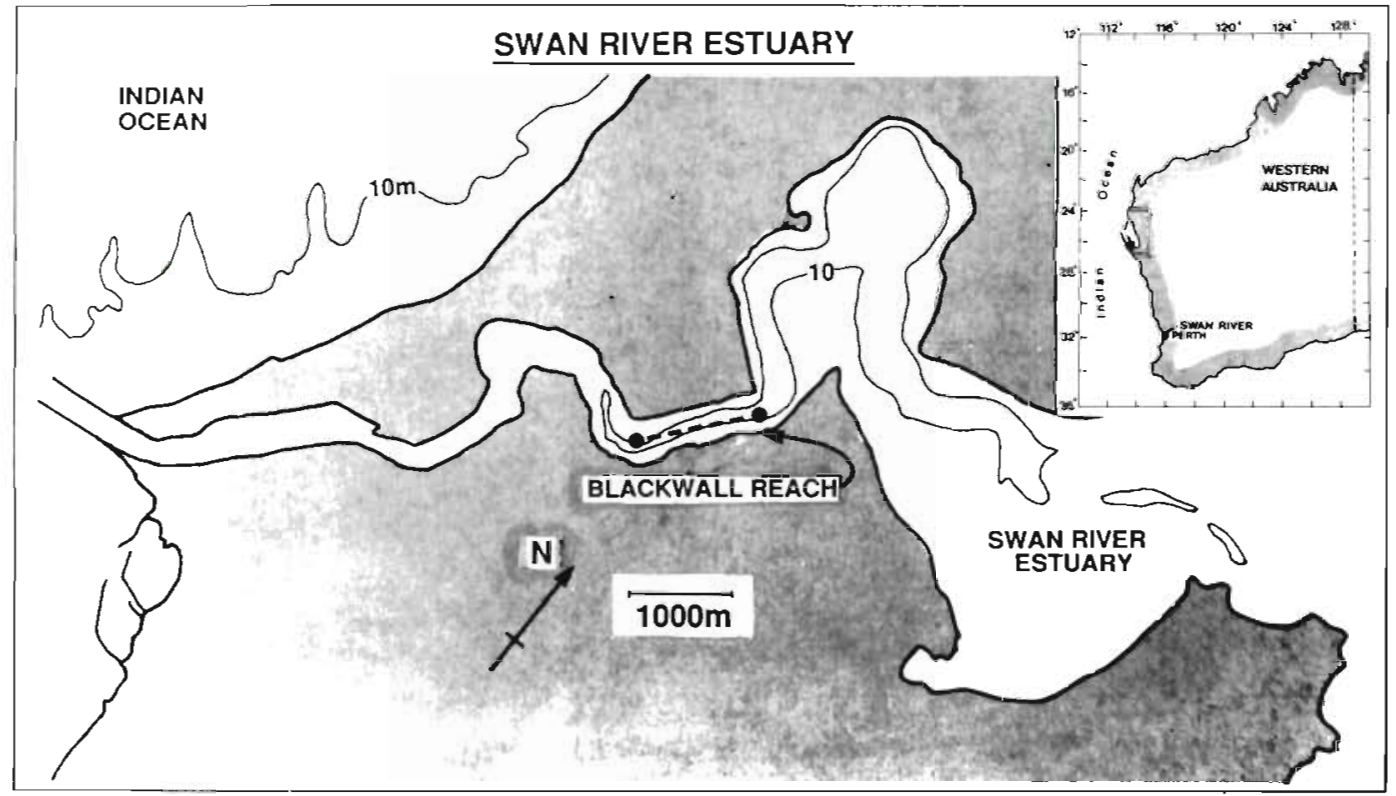

Fig. 1. Field work in Blackwall Reach. The boat that measured oxygen was anchored in the middle of the Reach. The boat that measured vertical diffusivities made a longitudinal transect of the Reach (-- $\bullet$ )

The estuary is seasonally stratified. During the rainy winter season, freshwater runoff creates a cool, low salinity surface layer 1 to $3 \mathrm{~m}$ thick. As spring progresses, an algal bloom, usually of diatoms Skeletonema costatum, develops in the surface waters. By late spring (Oct) this bloom declines. During the peak of the algal bloom (Aug-Scp), oxygen concenirations in the surface layer reach $30 \%$ above saturation but below the pycnocline oxygen concentrations can fall to near zero (Spencer 1956, Jack 1977).

During the experiment the estuary was strongly stratified with a water efflux of about $30 \mathrm{~cm} \mathrm{~s}^{-1}$. Tidal ebb flow began at about $0900 \mathrm{~h}$ and continued until late in the afternoon. Current speeds were determined with cruciform drogues which were placed in the upper $3 \mathrm{~m}$ of water and were followed for at least several hundred meters. The positions of the drogues were obtained with a microwave trisponder (Motorola Mini-Ranger) accurate to within $2 \mathrm{~m}$.

One vessel (R/V Djinnang II; Imberger \& Chapman 1986) equipped with a free-fall CTD fine-scale profiling system traversed the section (Fig. 1). The CTD probe was dropped at $1 \mathrm{~m} \mathrm{~s}^{-1}$ with a sensor readout frequency of 50 times $\mathrm{s}^{-1}$. Vertical profiles were obtained every $100 \mathrm{~m}$ along the $1200 \mathrm{~m}$ transect.

The tempreature and conductivity were first enhanced and matched as described in Fozdar et al. (1985) and the processed signals were used to calculate salinity and density. This could be done to a vertical resolution of about $2 \mathrm{~cm}$. The density profiles were then reordered as described in Imberger (1985) to pro- duce a density profile monotonically increasing with depth. The distance individual data points were moved in this process is termed the displacement scale, $h$ (Dillon 1982). The larger the displacement scale the greater is the potential energy of the individual overturn events in the water column. Dillon (1982) and Imberger \& Boashash (1986) have shown that for regions away from the immediate surface the turbulent kinetic energy dissipation $(\varepsilon)$ may be related to the displacement scale (h):

$$
\varepsilon=\mathrm{h}^{2} \mathrm{~N}^{3}
$$

where $\mathrm{N}^{3}=$ buoyancy frequency $\left(\mathrm{N}^{2}\right)$ raised to the $3 / 2$ power.

As discussed in detail in Imberger \& Boashash (1986) this relation is only valid for overturn events which have a Reynolds number of order unity. Dillon (1982) showed that provided the displacement scale was averaged over distances large compared to individual overturn events, then Eqn (4) yields an approximate estimate for the dissipation in and below the thermocline. In the mixed layer, where the surface input of turbulent kinetic energy dominates the energy budget, Eqn (4) will underestimate the dissipation.

Given the dissipation, an estimate of the vertical diffusion coefficient follows from the assumption that the turbulence is in equilibrium (Osborne 1980):

$$
K_{2}=0.2 \varepsilon / N^{2}
$$

where it was assumed that the flux Richardson number has a maximum value of 0.15 (Osborne 1980). Sub- 
stituting Eqn (4) into Eqn (5) leads to an estimate of $\mathrm{K}_{z}$ in terms of the displacement thickness $h$ :

$$
\mathrm{K}_{\mathrm{z}}=0.2 \mathrm{~h}^{2} \mathrm{~N}
$$

Eqn (6) was used to calculate vertical diffusivities directly from the buoyancy frequency $\left(\mathrm{N}^{2}\right)$ and the displacement scale.

A second vessel anchored at a station in the middle of the transect was equipped with a free-fall CTD with a newly developed fast response $(20 \mathrm{~ms})$ potentiostatic oxygen sensor (Karagounis et al. 1986). Depending upon the depth, 500 to 1000 data points were collected for each profile. The oxygen sensor was calibrated some days before, and again several hours after the experiment. Vertical profiles of oxygen were taken with the probe and correlated with the results of Winkler titrations of water samples collected in Van Dorn bottles. There was a linear correlation between oxygen determined by Winkler and by the sensor $\left(r^{2}=0.96\right.$, $n=20$ ). The oxygen sensor has a resolution of 5 mmole $\mathrm{O}_{2} \mathrm{~m}^{-3}$

Chlorophyll concentrations at discrete depths were estimated by in vivo fluorescence (Lorenzen 1966) with a Turner Designs 10 Fluorometer. The water intake and pumping system were designed to minimize the thickness of the sampled water layer. To serve as calibrations for the fluorometric readings, frequent samples were filtered on $0.45 \mu \mathrm{m}$ Millipore filters, extracted with $90 \%$ acetone and chlorophyll concentrations determined by spectrophotometry.

Soluble reactive phosphate $(\mathrm{P})$ was measured on GF/ $C$ filtered samples taken directly from the output hose of the fluorometer. The samples were reacted with molybdate, and the phosphomolybdate complex reduced with ascorbic acid for $10 \mathrm{~min}$ at $25^{\circ} \mathrm{C}$. Absorbances were measured in $10 \mathrm{~cm}$ cuvettes at $880 \mathrm{~nm}$. The precision of this method between 0.15 and 0.30 mmole $\mathrm{P} \mathrm{m}^{-3}$ was $7.6 \%$ with a detection limit of 0.01 mmole $\mathrm{P} \mathrm{m}^{-3}$.

Measurements of vertical diffusivity and oxygen variability were conducted over $20 \mathrm{~min}$, beginning at $1054 \mathrm{~h}$ on 29 July 1985. Profiles of chlorophyll and phosphate were taken during the morning and afternoon. Each profile of fluorescence and phosphate took about 30 min to accomplish.

\section{RESULTS}

The top $1 \mathrm{~m}$ of the water column in Blackwall Reach was weakly stratified. Between approximately 1 and $2.5 \mathrm{~m}$ there was a strong pycnocline (Fig. 2) created by a large change in salinity (Fig. 3). The water column beneath the pycnocline (here termed 'deep' water) was also weakly stratified. Temperature increased with

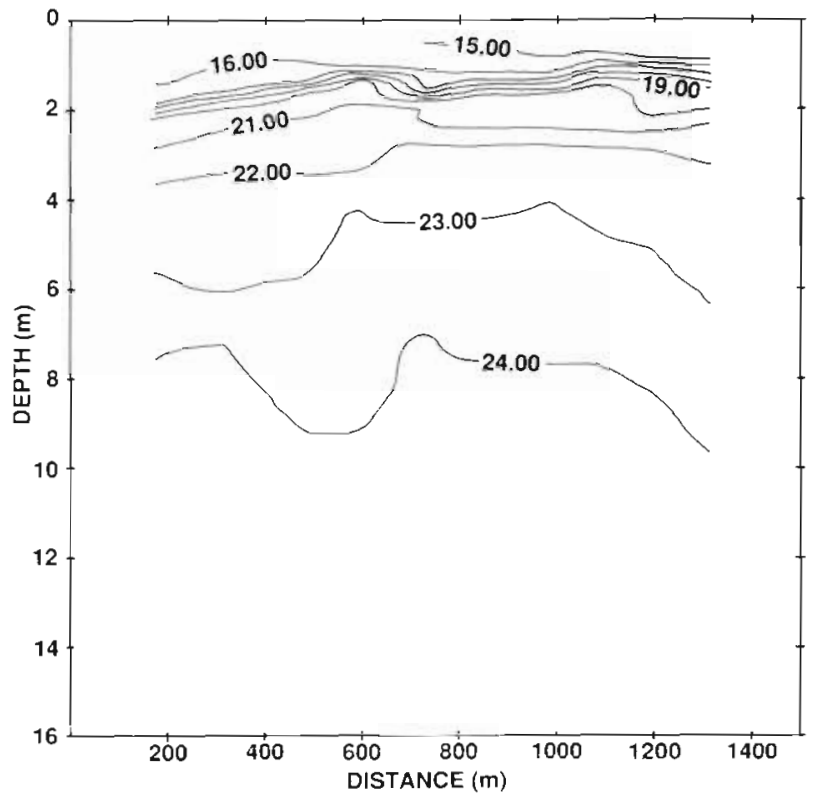

Fig. 2. Sigma-t values for Blackwall Reach. Note strong stratification at 1 to $2 \mathrm{~m}$ depth and internal wave movement

depth. The $2 \mathrm{~m}$ vertical displacements of the isopycnals in the deep water (sigma-t of 23.0 and 24.0; $\mathrm{kg} \mathrm{m}^{-3}-1000$ ) shown in Fig. 2 indicate the presence of internal waves in the section.

The vertical distribution of chlorophyll did not vary greatly at different sampling times (Fig. 4). The chlorophyll maximum, averaging about $24 \mu \mathrm{g} \mathrm{Chl} \mathrm{l}^{-1}$, was at the top of the pycnocline $(1$ to $1.5 \mathrm{~m}$ ) and rapidly decreased below the interface.

Four oxygen profiles taken within 20 min on 29 July 1985 showed an initial variability in the surface water, then a very strong and consistent decrease from about $350 \mathrm{mmole}_{2} \mathrm{~m}^{-3}$ to an oxygen minimum of approximately 225 mmole $\mathrm{O}_{2} \mathrm{~m}^{-3}$ (Fig. 5). The decrease in oxygen was from $30 \%$ above saturation to $15 \%$ below saturation at in situ temperatures and salinities. Below the oxygen minimum there was a large region of weakly stratified water in which the oxygen ranged from 210 to $275 \mathrm{mmole}_{2} \mathrm{~m}^{-3}$.

These data can be plotted with respect to time of sampling and, knowing the approximate current speed, the time axis converted to distance (Fig. 6). At a measured flow of $30 \mathrm{~cm} \mathrm{~s}^{-1}$, the 21 min sampling interval represents a distance of approximately $378 \mathrm{~m}$ of water in the Blackwall Reach. In this situation, the horizontal length dimension of oxygen patches was determined by taking sequential profiles at the fixed station. In Fig. 6, the sharp oxygen gradient between the surface layer and the deep water, and the patches of oxygen, are evident. The latter were approximately 1 to $2 \mathrm{~m}$ high and 100 to $200 \mathrm{~m}$ long in the deep water layer 
Fig. 3. Temperature and salinity increased with depth. Note 'steps' in the profiles, showing distinct layers

Fig. 4. Chlorophyll was high in surface water with maximum values at base of surface layer

Fig. 5. Oxygen concentration was above saturation in the surface layer and below saturation in bottom water. Note scale of variability in the deep water. Profiles taken between 1054 and 1113 h on 29 July 1985
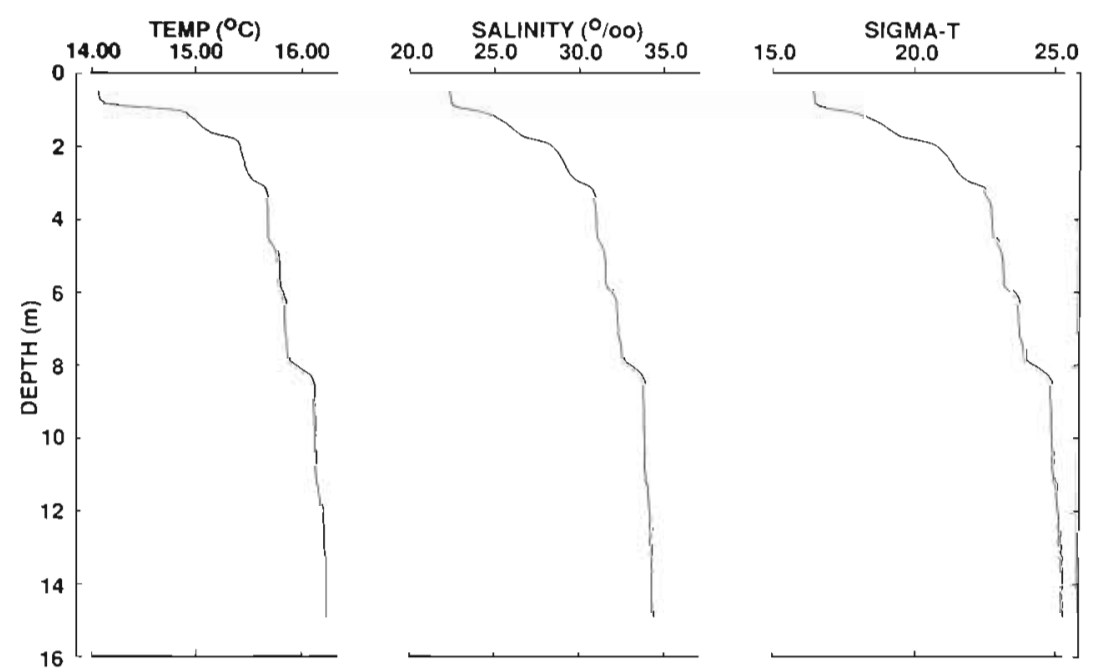

CHLOROPHYLL $(\mu \mathrm{g} / \mathrm{l})$
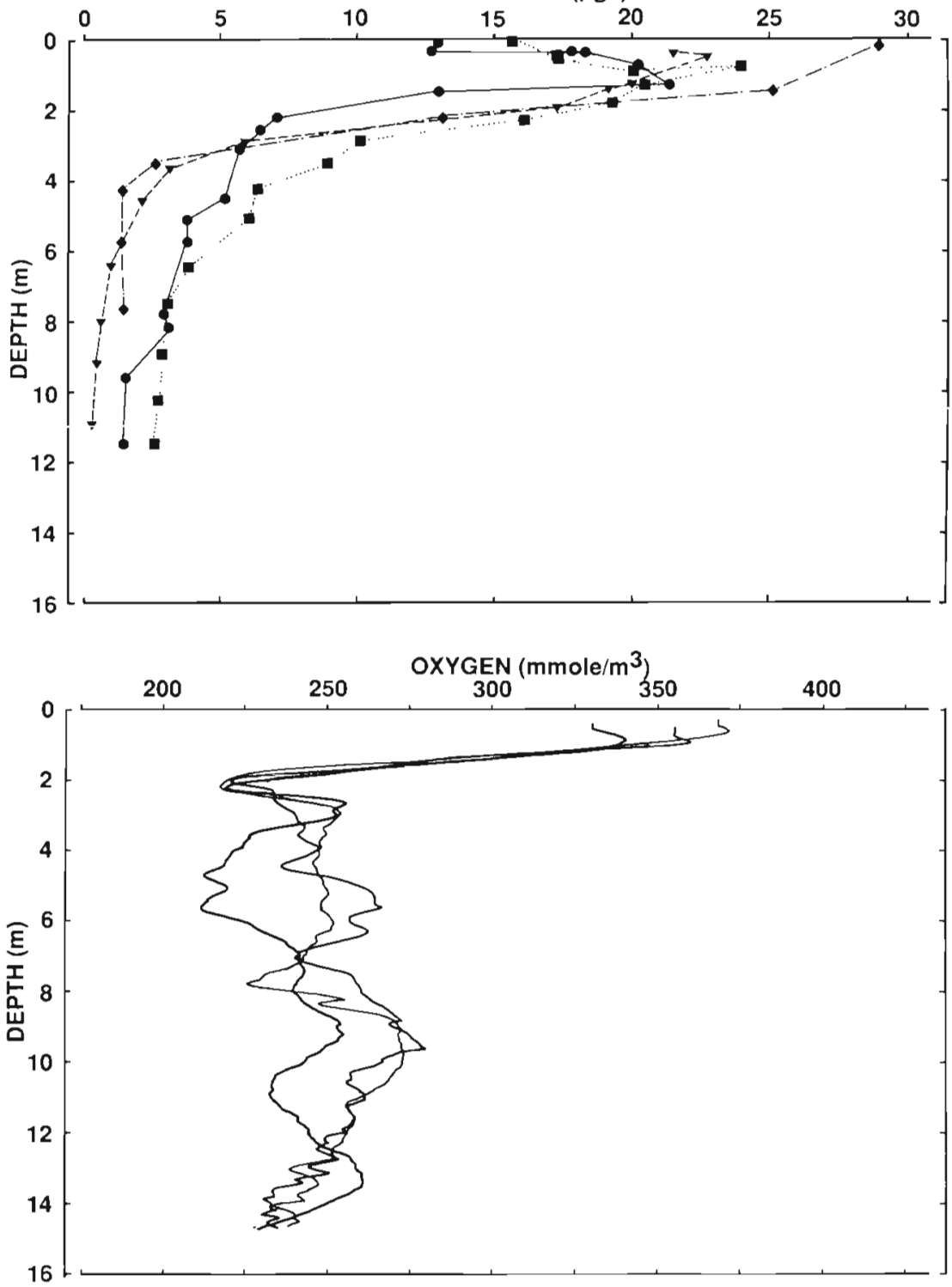


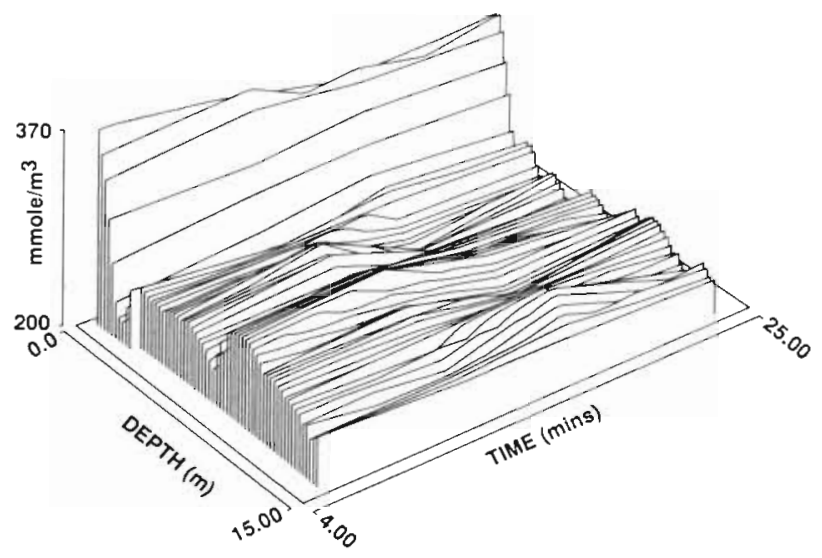

Fig. 6. Oxygen concentration along a section of the Blackwall Reach. Time axis represents approximately $378 \mathrm{~m}$ of water. Note high oxygen concentration surface layer and patches of oxygen in deep water. Same data as in Fig. 5

If the distribution of oxygen was determined only by physical mixing, then a plot of oxygen versus a conservative tracer such as temperature would be linear; non-linearity would indicate that other processes involving oxygen were faster than physical mixing. A plot of oxygen vs temperature (Fig. 7) shows the 3 main regions of the water column. (1) Oxygen from the surface to $1 \mathrm{~m}$ was only weakly correlated to temperature, most likely because of intense heating of the surface layer and oxygen gas release. (2) Between 1 and $2 \mathrm{~m}$, oxygen was linearly correlated with temperature. Even though mixing rates in the pycnocline are on average much lower than in the surface layer, defined as 0 to $0.5 \mathrm{~m}$, the linearity was a result of the large difference in oxygen concentration between surface and water below $1.5 \mathrm{~m}$. (3) In the deeper water layer, oxygen concentrations were not significantly related to temperature (Fig. 7) within space scales less than $2 \mathrm{~m}$ (coherence between oxygen and temperature was determined as a function of sampling frequency, or vertical length scale). Thus the variability of oxygen at space scales less than $2 \mathrm{~m}$ was caused by processes other than physical mixing. At space scales greater than $2 \mathrm{~m}$ the change in oxygen was related to temperature, indicating the overall change in oxygen was correlated to the thermal stratification of the water column. Only measurements with a resolution of less than $2 \mathrm{~m}$ would have revealed the vertical patchiness in this particular situation.

The value of vertical diffusivity (computed from Eqn [6]) throughout the longitudinal section of the Blackwall Reach varied by 4 orders of magnitude, from $10^{-6}$ to $10^{-2} \mathrm{~m}^{2} \mathrm{~s}^{-1}$ (Fig. 8). In the layer below the surface mixed layer between 0.5 and $1.5 \mathrm{~m}$ there were 2 strong mixing events which created regions of intense vertical mixing at the base of the surface layer (see Fig. $2 \& 8, K_{z}=10^{-2}$ to $10^{-3}$ ). These isolated regions of very rapid mixing are characteristic of shear-induced overturning. Below the pycnocline, vertical mixing decreased to the levels of molecular diffusion, $10^{-5}$ to $10^{-6} \mathrm{~m}^{2} \mathrm{~s}^{-1}$, with occasional mixing events occurring throughout the water column, particularly near the bottom (Fig. 8). These mixing events were probably a result of shear induced by internal waves and currents.

In order to estimate an average vertical diffusivity $\left(\mathrm{K}_{2}\right)$ we assumed that the longitudinal section (Fig. 8) represented an instantaneous measurement of the average dissipation of energy by mixing processes, implying that the sample of vertical diffusivities shown was a statistical representation of these mixing events. Thus an average vertical diffusivity was determined for different depth intervals by multiplying each verti-

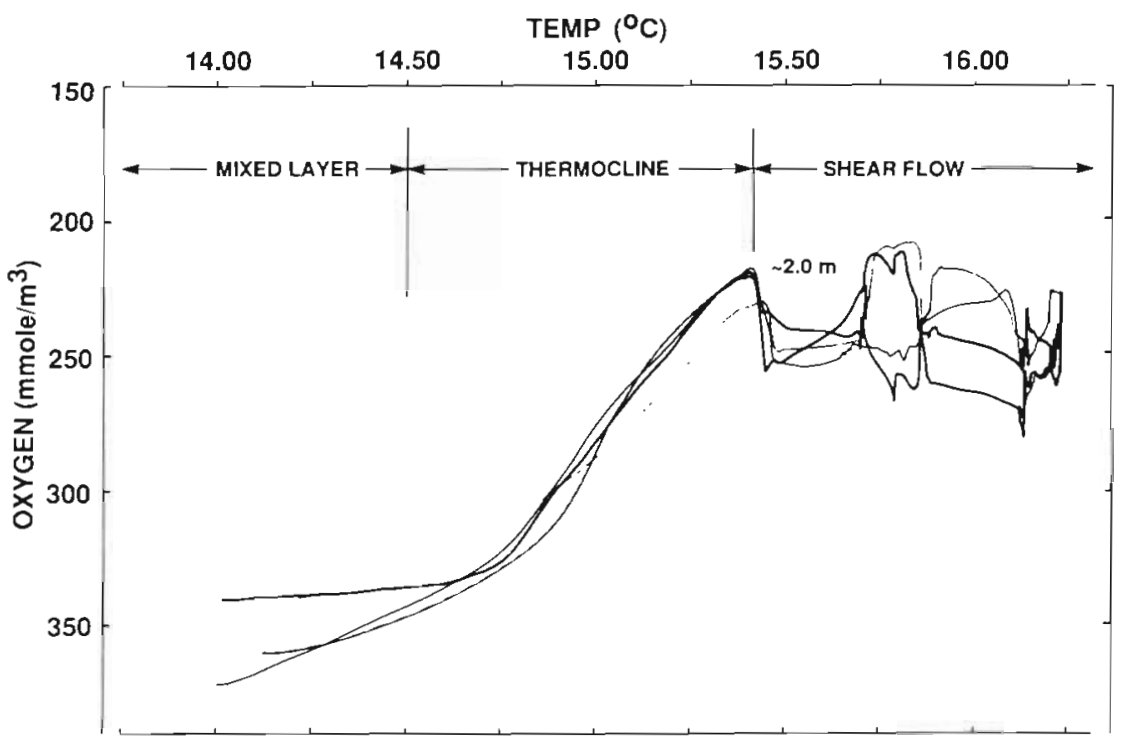

Fig. 7. Oxygen versus temperature, showing oxygen and temperature were not correlated in the deep water 


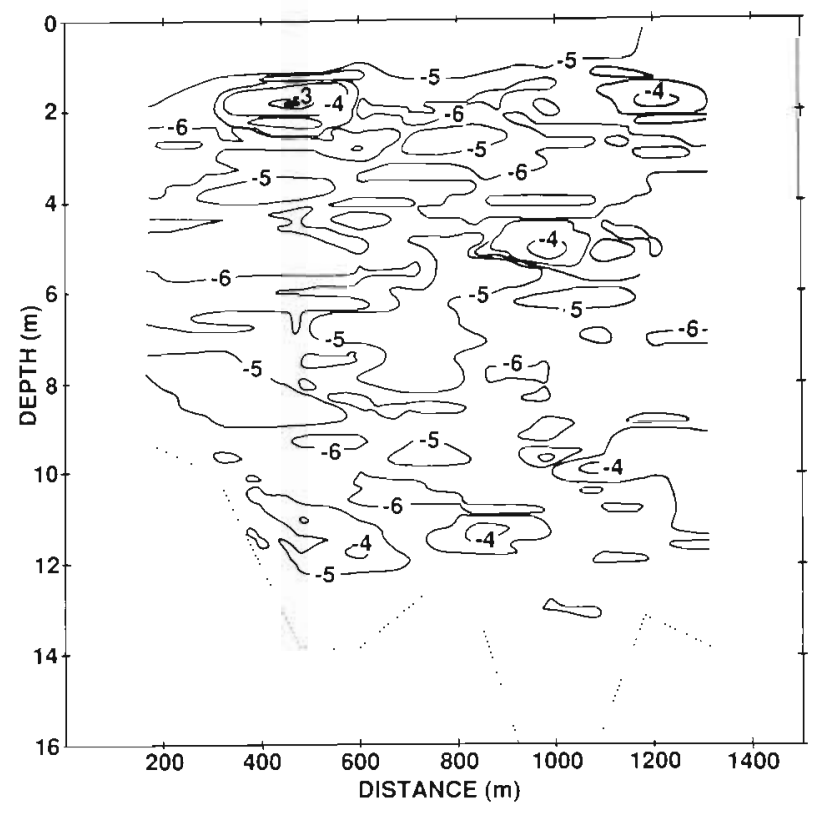

Fig. 8. Contours of vertical diffusivity $\left(\log \mathrm{m}^{2} \mathrm{~s}^{-1}\right)$. Note areas of intense mixing at base of surface layer $(1.5$ to $2.0 \mathrm{~m})$ and near the bottom. The solid dark spot at the base of the mixed layer indicates a vertical diffusivity of $10^{-2}$. Ten profiles were made approximately $100 \mathrm{~m}$ apart along the $1200 \mathrm{~m}$ transect

cal diffusivity by the percent area it covered in Fig. 8. The weighted average value of vertical diffusivity from 0.5 to $2 \mathrm{~m}$ was $8.2 \times 10^{-4} \mathrm{~m}^{2} \mathrm{~s}^{-1}$; from 2 to $4 \mathrm{~m}, 1.3 \times$ $10^{-4} \mathrm{~m}^{2} \mathrm{~s}^{-1}$; and from $4 \mathrm{~m}$ to the bottom, $1.7 \times 10^{-4}$ $\mathrm{m}^{2} \mathrm{~s}^{-1}$ Our data were insufficientit to detentnine an average mixing rate of the sharp pycnocline layer.

The height of the oxygen patches in the deep water was approximately 1 to $2 \mathrm{~m}$ (Fig. 6). The time scale to mix water $1 \mathrm{~m}$, according to Eqn (1), is $1.6 \mathrm{~h}(1 / 1.7 \times$ $\left.10^{-4} \mathrm{~m}^{2} \mathrm{~s}^{-1}\right)$. Likewise the time scale to $\operatorname{mix}$ water $2 \mathrm{~m}$ is $6.5 \mathrm{~h}$. Thus the average age of these discrete volumes of water was between 2 and $6 \mathrm{~h}$. If the vertical mixing was caused by shear from internal waves and current, then the horizontal dispersion from the same shear would have mixed the patches horizontally. The extent of the horizontal dispersion can be approximated by a knowledge of the shear (Okubo 1980). In the absence of accurate measurements of the vertical change in current speed it is difficult to make further calculations. However the length of the oxygen patch (100 to $200 \mathrm{~m}$, Fig. 6) is about the appropriate distance over which a volume of water would be mixed given a reasonable horizontal dispersion coefficient and the age of the patches. Thus the dimensions of the oxygen patches appear to be consistent with the idea that shear caused the vertical and horizontal mixing.

The patches of oxygen in the deeper layers could have been formed by injection of oxygen from the surface layer, different boundary fluxes of oxygen or in vivo metabolism. Because oxygen and temperature were not correlated within these patches, they were not formed by mixing alone. Thus oxygen metabolism proceeded at a rate sufficiently fast to create discrete patches of oxygen which grew until they were eventually mixed with neighboring water by a mixing event.

By assuming that the characteristic size of the patches was a result of a balance between average mixing and average metabolism, the overall metabolic rate of oxygen in the deep water can be estimated. Rearranging Eqn (3), we calculate the metabolic rate, a:

$$
\mathrm{a}=\mathrm{C}_{0} \mathrm{~K}_{\mathrm{z}} / \mathrm{L}^{2}
$$

where $\mathrm{C}_{0}=$ the concentration difference between patches. The deep water patches were approximately $2 \mathrm{~m}$ high (Fig. 6) with an average difference between the maxima and minima of 25 mmole $\mathrm{O}_{2} \mathrm{~m}^{-3}$. The vertical diffusivity was $1.7 \times 10^{-4} \mathrm{~m}^{2} \mathrm{~s}^{-1}$. Therefore we estimate a net oxygen uptake rate of $3.8 \mathrm{mmole}_{2}$ $\mathrm{m}^{-3} \mathrm{~h}^{-1}$

A similar calculation can be made for the surface layer. The height of the surface patch was again approximately $2 \mathrm{~m}$, the difference in oxygen between the surface and deep patches was 125 mmole $\mathrm{O}_{2} \mathrm{~m}^{-3}$, and $\mathrm{K}_{\mathrm{z}}$ was $8.2 \times 10^{-4} \mathrm{~m}^{2} \mathrm{~s}^{-1}$; thus the rate of oxygen production was 92 mmole $\mathrm{O}_{2} \mathrm{~m}^{-3} \mathrm{~h}^{-1}$. Extrapolating this rate over the $2 \mathrm{~m}$ layer gives a production of 184 mmole $\mathrm{O}_{2} \mathrm{~m}^{-2} \mathrm{~h}^{-1}$. Considering the high chlorophyll levels (Fig. 4) the estimated oxygen uptake and production rates are reasonable and give some confidence to our interpretation of the observed variability.

Phosphate in the upper $1 \mathrm{~m}$ was low and then increased with depth. Note however that each profile showed high vertical variability (Fig. 9). These data can be interpreted in a similar manner to those for oxygen. Variability within each profile represents patches of phosphate encountered during the $1 / 2 \mathrm{~h}$ sampling period. Thus variability could be used to delineate the vertical patch height, then to calculate the release rate of phosphate, but the water was not sampled rapidly enough to clearly resolve the dimensions of the patches. Thus it is important to realize that the maxima and minima found in any single profile do not necessarily represent a true picture of the vertical layering of the water column. The apparent maxima and minima were probably created by patches of phosphate, in the same way that the apparent maxima and minima of oxygen were merely expressions of the vertical height of the oxygen patches. To achieve an 'average' vertical gradient of phosphate, much more data would be required.

The lowest concentrations of phosphate in the deep water were observed in the profile taken at an early stage of the ebb tide, whereas higher phosphate con- 


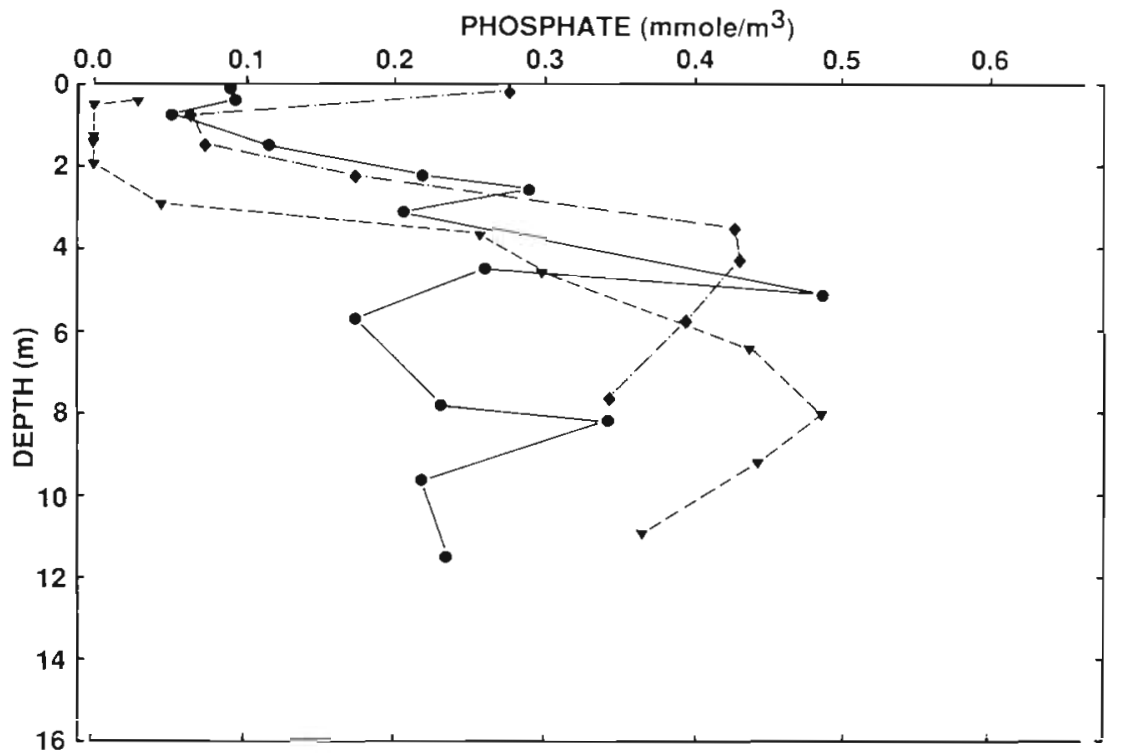

Fig. 9. Soluble reactive phosphate versus depth, showing vertical variability in phosphate. $(\bullet)$ Early ebb tide; $(\nabla, \bullet)$ late ebb tide centrations were measured at the later stage of the ebb tide (Fig. 9). These results indicate that the deep water of the estuary was a source of phosphate. The difference between the profiles represents a shift in the mean concentration of phosphate. Superimposed upon the mean changes were patches of elevated phosphate, which created the variability observed in the profiles.

If the source of phosphate was from remineralization of organic material, the increase in the mean phosphate should be correlated with a decrease in the mean oxygen. Oxygen profiles taken toward the end of the ebb tide, in the afternoon, indicated that the oxygen in deep water decreased from the morning values (compare Fig. $5 \& 10$ ). The variability of oxygen in the afternoon profiles was less than in the morning pro- files. Due to equipment failure we have no vertical diffusivity data for the afternoon to interpret this variability. However, the net shift in mean phosphate concentration was approximately 0.16 mmole $\mathrm{P} \mathrm{m}^{-3}$ while the net change in oxygen was $40 \mathrm{mmole}_{2} \mathrm{~m}^{-3}$; thus the molar ratio of remineralization was about 250:1. This ratio would be consistent with the remineralization of planktonic organic material (of composition near the Redfield ratio) plus some inorganic release of phosphate from the sediments, or, the ratio would be consistent with the remineralization of a mixture of planktonic and benthic organic material (benthic material has a C:P ratio near 500:1; Atkinson \& Smith 1983). We cannot determine how different boundary fluxes of oxygen and phosphate influenced this ratio.

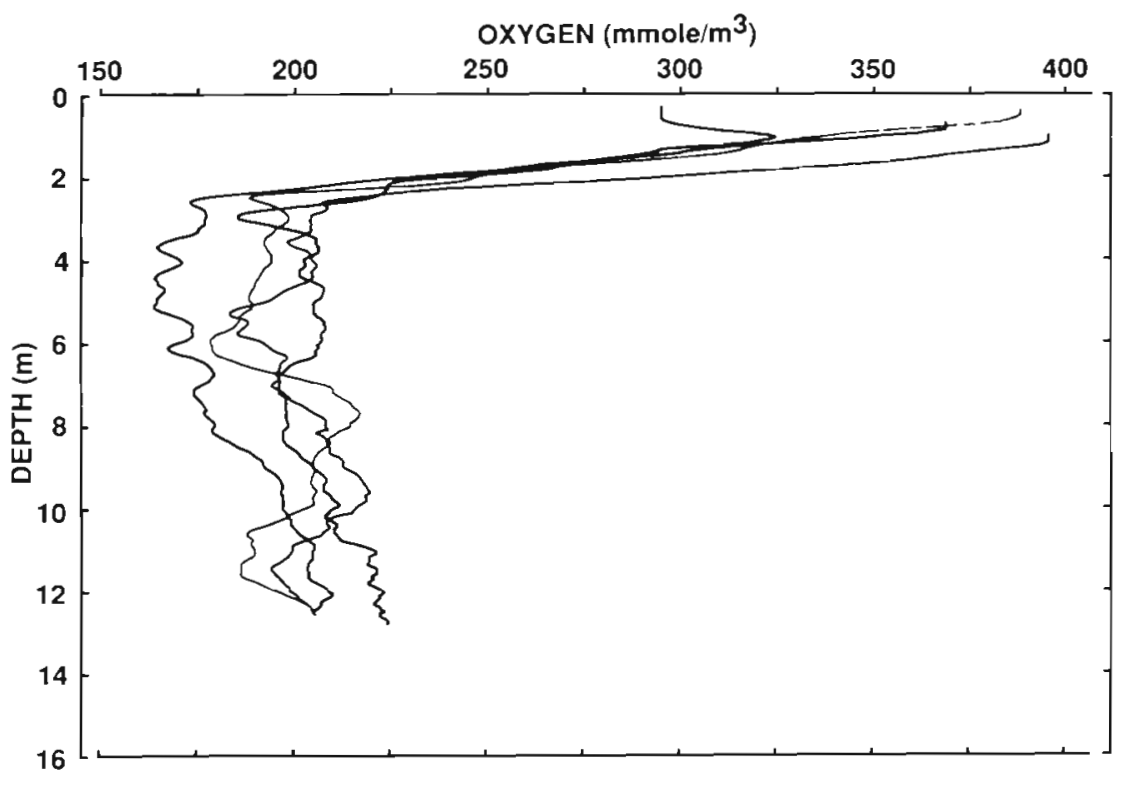

Fig. 10. Oxygen concentration for 4 profiles taken at the last stage of ebb tide between 1458 and $1546 \mathrm{~h}$ on 29 July 1985. The deep water oxygen concentrations were lower than the earlier profiles (Fig. 5) 


\section{DISCUSSION}

Vertical variability of dissolved oxygen and phosphate in the Blackwell Reach can be explained by a balance between vertical mixing and metabolism. Patches or clouds of oxygen are formed as a result of heterogeneous distributions of organisms in the water column, and by differences in net metabolism in the water and on the bottom. These patches, which are embedded in the water flow, grow and occasionally coalesce with neighboring ones. When either mixing or metabolic rates change, the minimum size of the patch will also change. Thus daily and seasonal changes in both mixing and metabolism may cause variations in the characteristic length and height scales of patches.

Each biologically mediated quantity will have its own minimum length and height scale, independent of other quantities. The particular dimensions of each patch are determined by the turnover rate of that biological quantity and the mixing rate (Eqn [3]). Thus organisms may experience an environment in which each nutrient or metabolite could have a different size patch. These patchy environments combine to give observed mean values (e.g. compare morning and afternoon oxygen and phosphate profiles).

We now comment on the implication of patchiness on sampling strategies. We suggest that the correct scale to sample for mean trends is 10 -fold greater than the estimated minimum patch size, based on the fact that our predictions derive from an order of magnitude calculation. In large basins or embayments, sampling on small space scales (about the size of a patch) will only result in poor, unrepresentative data sets. It must also be remembered that if there are different boundary conditions for 2 compounds, a plot of one compound versus the other will not necessarily give a true representation of the relation of the fluxes (Wyrtki 1962, Okubo 1980); nor will the internal fluxes or the patches of the compound be necessarily correlated. This is particularly true in estuarine and coastal environments where the boundaries are often extremely patchy with very different boundary flux conditions for the different compounds.

In contrast to the above discussion, to resolve the variability of a quantity that an organism might experience, sampling should be at time or space scales of the minimum patch size. A benthic or sessile organism in a productive estuary such as the Swan River experiences changes in its physical environment on space scales of 10 's of meters and time scales of minutes. Sampling on larger scales will not show the environmental variability that such an organism might encounter.

We suggest that investigators should use simple scaling arguments such as the ones in this analysis to determine time and space scales for sampling. For example, consider the space scale of oxygen variability immediately below the mixed layer in an oligotrophic ocean. Using Eqn (3), the minimum vertical height of a patch of oxygen can be estimated. Assuming a respiration rate (a) below the mixed layer of about $47 \mu$ mole $\mathrm{O}_{2} \mathrm{~m}^{-3} \mathrm{~d}^{-1}$ (Jenkins 1982), a vertical mixing rate $\left(\mathrm{K}_{z}\right)$ of $10^{-5} \mathrm{~m}^{2} \mathrm{~s}^{-1}$, and an oxygen concentration $\left(\mathrm{C}_{0}\right)$ difference of $10 \mathrm{mmole} \mathrm{O}_{2} \mathrm{~m}^{-3}, \mathrm{~L}$ is about $40 \mathrm{~m}$. Thus variability measured on scales of 10 's of meters probably will not be correlated with the mean vertical or horizontal gradients. Variability of oxygen on these scales has been observed in the Western Pacific (Lukas \& Karl pers. comm.). Likewise other biogeochemical compounds would be expected to exhibit variability or patchiness that is uncorrelated with the mean. Metabolic compounds that turnover quickly and organisms that grow rapidly will tend to have relatively small minimum patch sizes. Thus, it should not be surprising that investigators find relatively high variability among closely spaced samples. We suggest that such variability in measurements of biological quantities and rate processes is not artifactual but reflects the existence of different patches created by the interaction of mixing and metabolism. A better understanding of the ecological implications of this kind of patchiness remains a goal for future research.

\section{Conclusion}

The observed oxygen patch size and distribution was found to be consistent with the hypothesis that local oxygen production was balanced by vertical mixing.

Acknowledgements. The oxygen sensor was obtained from Professor C. C. Liu of the Electronics Design Center, Case Western Reserve University; it was fabricated using the facilities supported by NIH Grant No. RR02024. Thanks to colleagues at the University of Hawaii Oceanography Department for comments on early drafts of the manuscript. JI would also like to thank the Fairchild Fellowship program for enabling his visit to Caltech. This work was supported by Australian Marine Science and Technology Grant No. 84-1896.

\section{LITERATURE CITED}

Atkinson, M. J., Smith, S. V. (1983). C:N:P ratios of benthic marine plants. Limnol. Oceanogr. 28 (3): 568-574

Denman, K. L., Platt, T. (1976). The variance spectrum of phytoplankton in a turbulent ocean. J. mar. Res. 34 : 593-601

Dillon, T. M. (1982). Vertical overturns: A comparison of Thorpe and Ozmidov length scales. J. geophys. Res. 87: 9601-9613

Fischer, H. B., List, E. J., Koh, R. C. Y., Imberger, J., Brooks, N. H. (1979). Mixing in inland and coastal waters. Academic Press, New York 
Fozdar, F. M،, Parker, G. J., Imberger, J. (1985). Matching temperature and conductivity sensor response characteristics. J. phys. Oceanogr. 15 (11): 1557-1569

Imberger, J. (1977). On the validity of water quality models. Proceeding of the 17th Congress of the LAHR (Int. Ass. of Hydraulics Res.), Baden-Baden 6: 292-303

Imberger, J. (1985). The diumal mixed layer Limnol. Oceanogr. 30: 737-770

Imberger, J., Boashash, B. (1986). Application of the WignerVille distribution to temperature gradient microstructure: A new technique to study small scale variations. J. phys. Oceanogr. (in press)

Imberger, J., Chapman, R. (1986). Djinnang II: A facility to study mixing in stratified waters. In: Kjerve, B. (ed.) Hydrodynamics of estuaries. CRC Press, Boca Raton (in press)

Imberger, J., Berman, T., Christian, R. R., Sherr, E. B., Whitney, D. E., Pomeroy, L. R., Wiegert, D. E., Wiebe, W. J. (1983). The influences of water motion on the distribution and transport of materials in a salt marsh estuary. Limnol. Oceanogr. 28: 201-214

Jack, P. N. (1977). Seasonal variations in the water of the Swan River. Government Chemical Laboratories, Western Australia, Report No. 14, p. 1-26

Jenkins, W. J. (1982). Oxygen utilization rates in North Atlantic subtropical gyre and primary production in oligotrophic systems. Nature, Lond. 300: 246-248

Karagounis, V., Lun, L., Liu, C. C. (1986). A thick-film multiple component cathode three-electrode oxygen sensor. IEEE Transactions on Biomedical Engineering 33 (2): $108-1.13$

Kierstead, H., Slobodkin, L. B. (1953). The size of water masses containing a plankton bloom. J. mar. Res. 12: $141-147$

Lewis, M. R., Platt, T. (1982). Scales of variability in estuarine ecosystems. In: Kennedy, V. S. (ed.) Estuarine comparisons. Academic Press, New York, p. 3-20

Lorenzen, C. C. (1966). A method for the continuous measurement of in vivo chlorophyll concentrations. Deep Sea Res. 13: $223-227$

Okubo, A. (1977). Horizontal dispersion and critical scales for phytoplankton growth. In: Steele, J. (ed.) Spatial patterns in plankton communities. Plenum Press, New York, p. $21-43$

Okubo, A. (1980). Diffusion and ecological problems: mathematical models. Biomathematics Vol. 10. SpringerVerlag, New York

Osborne, T. R. (1980). Estimate of local rate of vertical diffusion from dissipation measurements. J. phys. Oceanogr. 10: $83-89$

Platt, T., Harrison, W. G. (1985). Biogenic fluxes of carbon and oxygen in the ocean. Nature, Lond. 318: 55-58

Platt, T., Mann, K. H., Ulanowicz, R. E. (1981). Mathematical models in biological oceanography. Monographs on Oceanographic Methodology, UNESCO Press, Paris

Pomeroy, L. R., Imberger, J. (1981). The physical and chemical environment. In: Pomeroy, L. R., Wiegert, R. G. (ed.) The ecology of a salt marsh. Ecological Studies 38 Springer-Verlag, New York, p. 21-36

Skellam, J. G. (1951). Random dispersal in theoretical populations. Biometrika 38: 196-218

Spencer, R. S. (1956). Studies in Australian estuarine hydrology II. The Swan River. Aust. J. mar. Freshwat. Res. 7: 193-253

Steele, J. H. (1978). Some comments on plankton patches. In: Steele, J. H. (ed.) Spatial patterns in plankton communities. Plenum Press, New York, p. 1-21

Wyrtki, K. (1962). The oxygen minimum in relation to ocean circulation. Deep Sea Res. 9: 11-23 